\title{
The Pilot Aptitude Tester e a seleção de pilotos
}

\author{
Maurício Pereira da Costa ${ }^{1}$, Irai Cristina Boccato Alves \\ Instituto de Psicologia da Universidade de São Paulo, São Paulo-SP, Brasil
}

\section{RESUMO}

Desde a Primeira Guerra Mundial, há um grande investimento na seleção de pilotos militares por parte das Forças Aéreas com o intuito de diminuir os altos custos envolvidos na formação do piloto militar por meio da diminuição do atrito (fracasso) na instrução aérea. Porém, foi na Segunda Guerra Mundial que os testes psicológicos, que mensuravam aptidões psicomotoras e cognitivas, passaram a ser mais efetivos em predizer a aptidão para a pilotagem, contribuindo para a diminuição do atrito encontrado nas instruções aéreas. Um dos poucos testes psicológicos construídos especialmente para a seleção de pilotos é o The Pilot Aptitude Tester (PILAPT), uma bateria de seis testes que avaliam aptidões psicomotoras e cognitivas voltadas para a atividade aérea, adquirido pela Força Aérea Brasileira para ser inserido em sua seleção de pilotos militares.

Palavras-chave: psicologia aeronáutica; testes de aptidões específicas; seleção de recursos humanos; avaliação psicológica.

\section{ABSTRACT - The Pilot Aptitude Tester and the pilot selection}

Since World War I, the Air Forces has made a major investment in the selection of military pilots with the purpose of reducing the high costs involved in military pilot training by reducing attrition (failure) in flight instruction. But it was in World War II that psychological tests that assess psychomotor and cognitive abilities became more effective in predicting aptitude for piloting, contributing to the reduction of attrition found in flight instructions. One of the few psychological tests designed for selecting pilots is The Pilot Aptitude Tester (PILAPT), a series of six tests that assess cognitive and psychomotor abilities with regard to flight activity, and which was acquired by the Brazilian Air Force to be used in their selection of military pilots.

Keywords: aeronautics psychology; specific aptitude tests; human resources selection; psychological assessment.

\section{RESUMEN - The Pilot Aptitude Tester y la Selección de Pilotos}

Desde la Primera Guerra Mundial hay una gran inversión en la selección de los pilotos militares de la Fuerza Aérea con el fin de reducir los altos costos involucrados en la formación de pilotos militares, reduciendo la deserción (fracaso) en la instrucción de vuelo. Pero fue la Segunda Guerra Mundial que los tests psicológicos que mensuraban habilidades psicomotoras y cognitivas, se hicieron más eficaces en la predicción de la aptitud para pilotar, lo que contribuyen a la reducción de la deserción que se encuentra en las instrucciones de vuelo. Una de las pocas pruebas dirigidas especialmente para la selección de los pilotos es The Pilot Aptitude Tester (PILAPT), una batería de seis pruebas que evalúan las habilidades cognitivas y psicomotoras orientadas hacia la actividad aérea, adquirido por la Fuerza Aérea Brasileña para ser insertado en su selección de pilotos militares.

Palabras clave: psicología aeronáutica; prueba de las habilidades específicas; selección de personal; evaluación psicológica.

O alto custo envolvido na formação de um aviador, principalmente de um piloto militar, vem fazendo com que haja investimentos por parte das Forças Armadas em pesquisas e desenvolvimento de instrumentos que possam avaliar características compatíveis com as de um aviador (Griffin \& Koonce, 1996). Com isso, a seleção de candidatos a pilotos militares que tenham maiores chances de obter sucesso na instrução aérea é melhorada e os custos investidos em candidatos que fracassam na instrução aérea são diminuídos.

Segundo Griffin e Koonce (1996, p. 127):
[... a Segunda Guerra Mundial produziu uma necessidade de pilotos que poderiam ser treinados em um curto período de tempo e o aumento do custo de treinamento enfatizou a necessidade de reduzir o número de pilotos em treinamento que iriam falhar.

Melhorando a seleção de pilotos, são diminuídos o fracasso (desligamentos) existente na instrução aérea e, consequentemente, os gastos envolvidos na formação, resultando em ganho financeiro considerável para a instituição. O nível de desempenho esperado para essa 
formação também aumenta, já que são selecionados indivíduos com maiores habilidades para a atividade aérea, melhorando também o nível de segurança de voo.

Historicamente, os avanços na seleção de pilotos ocorreram principalmente na aviação militar, tendo em vista os recursos financeiros disponíveis e também pelo interesse em diminuir gastos com a instrução aérea, sendo que nos últimos anos o desenvolvimento de testes informatizados vem predominando nessa área (Hunter \& Burke, 1995; Griffin \& Koonce, 1996).

De acordo com Hunter e Burke (1995), os ganhos financeiros obtidos pela seleção de pilotos ocorrem porque os testes avaliam habilidades exigidas para a atividade aérea, que são transformadas em produtividade. As falhas no treinamento de pilotos custam tanto para a instituição quanto para o indivíduo. A instituição investe em treinamento que é perdido quando o indivíduo não alcança êxito no aprendizado da atividade aérea e é desligado do curso de formação de pilotos.

A média de atrito (desligamentos) na instrução aérea básica no $2^{\circ}$ Esquadrão de Instrução Aérea (EIA) na Academia da Força Aérea (AFA) por motivo de inaptidão para a pilotagem militar é de $23 \%$, tendo por base os anos de 2000 até 2010. Com o objetivo de diminuir esse atrito existente na instrução aérea e, em consequência, os custos envolvidos na formação do piloto militar brasileiro, a Força Aérea Brasileira (FAB) procurou melhorar a seleção na entrada dos cadetes aviadores na AFA. Por essa razão, foi adquirido pela $\mathrm{FAB}$, no ano de 2004, o sistema The Pilot Aptitude Tester (PILAPT), instrumento de seleção de pilotos desenvolvido pelas empresas Psytech e Peotech (Inglaterra) para ser implantando na seleção de pilotos militares da AFA. No Brasil, o teste recebeu a denominação de Teste de Aptidão para a Pilotagem Militar (TAPMIL), sendo que sua normatização foi específica para as necessidades da FAB.

O sistema TAPMIL possui uma bateria de seis testes psicológicos que visam avaliar o potencial de aprendizado para atividade aérea. Trata-se de um teste totalmente informatizado, possuindo estações de teste individual controladas por um servidor e sua aplicação ocorre de maneira individual ou coletiva, porém, a execução do teste é realizada de forma individualizada. As respostas às tarefas dos testes são dadas por joystick, mouse ou teclado especialmente desenvolvido para o teste. O sistema possui ainda fone de ouvido para o fornecimento de algumas instruções auditivas para o testando. As instruções para a realização de cada teste são autoexplicativas e apresentadas na tela do computador de cada examinando, possuindo exemplos e práticas para assegurar o entendimento da atividade a ser realizada, dispensando o fornecimento de explicações complementares pelo aplicador.

O teste utiliza a medida de amostra de trabalho, que consiste em "simular uma situação em que o desempenho requerido para realizar uma tarefa é similar ao desempenho utilizado na realização real do trabalho"
(Hunter \& Burke, 1995, p. 104). Os seis testes avaliam as habilidades psicomotoras, cognitivas e em tarefas múltiplas (psicomotoras e cognitivas combinadas) dos candidatos a uma vaga no Curso de Formação de Oficiais Aviadores (CFOAV) da AFA. A coordenação motora é investigada no instrumento de forma similar à produzida por um piloto que esteja recebendo instruções para realizar um voo. As variáveis mensuradas pelos testes do sistema são (Kokorian, 1999): capacidade psicomotora, raciocínio espacial, processamento de informações, memória de trabalho, velocidade e precisão de respostas, atenção seletiva e dinâmica, habilidade em gerenciar múltiplas tarefas (habilidades psicomotora e cognitiva combinadas).

Ao término da execução do teste, o aplicador (e somente ele) tem acesso ao resultado do candidato, que é gerado pelo próprio software do teste. Os resultados brutos de cada teste são transformados em Nota T, para posteriormente ser obtido o resultado geral do teste. Os resultados brutos dos testes e o resultado geral são transformados em estenos (stens - standard ten). O esteno é uma transformação dos resultados brutos que tem como finalidade principal buscar uma normalização da distribuição dos resultados da amostragem em uma escala de 1 (baixo) a 10 (alto).

Após alguns anos de criação de banco de dados e estudos comparando o resultado no teste com o desempenho na instrução aérea, foi realizada a normatização e validação do teste (contendo estudos preditivos) que levou à elaboração do manual brasileiro. Esse manual foi elaborado com base na Dissertação de Mestrado de Costa (2010). O referido manual do teste possui ainda estudos de análise fatorial, análise de itens, precisão teste-reteste, consistência interna, regressão, correlação e gráfico de expectativa; segundo Anastasi e Urbina (2000, p. 81), "uma das maneiras de interpretar o significado de um escore de teste é em termos do desempenho de critério esperado da pessoa, como em um programa de treinamento ou em uma função". Um gráfico de expectativa nos dá a probabilidade de diferentes resultados de critério (interpretação do desempenho) para pessoas que obtêm cada resultado de teste, ou seja, a partir do resultado de cada candidato pode-se saber quais são as chances dele obter sucesso. Existem estudos comparativos dos resultados nacionais com os resultados apresentados com o teste em outras forças aéreas que utilizam o mesmo sistema de seleção.

No ano de 2009, o teste recebeu aprovação do Sistema de Avaliação dos Testes Psicológicos (SATEPSI) do Conselho Federal de Psicologia (CFP), e desde então vem sendo utilizado no processo seletivo para entrada no CFOAV da AFA. Para utilizar o TAPMIL no processo seletivo, foram realizados estudos para o estabelecimento de desempenho mínimo (ponto de corte) a ser atingido pelo candidato no resultado geral do TAPMIL de acordo com o desempenho esperado na instrução aérea da AFA (gráfico de expectativa). Para o estabelecimento do ponto 
de corte, muitos fatores são analisados, não sendo uma decisão arbitrária, mas resultado das pesquisas.

As pesquisas indicaram uma relação direta entre o resultado do TAPMIL e o desempenho no voo. Quanto maior o resultado no teste, maiores são as notas finais atribuídas na instrução aérea e as chances de o cadete concluir o curso com êxito, sendo que o inverso também ocorre. Em estudo de meta-análise, Martinussem (1996) relata que a melhor maneira de se predizer a performance esperada de um indivíduo na atividade aérea é pelo uso do critério sucesso/fracasso na instrução.

Antes da implantação do TAPMIL, a média de desligamento do CFOAV por inaptidão para a pilotagem militar era de $23 \%$ por turma que iniciava o curso de pilotagem. Após a utilização do teste no processo seletivo, essa porcentagem vem diminuindo gradativamente, chegando a $12 \%$ de cadetes desligados por inaptidão para a pilotagem militar em 2014 e a 11\% em 2015. Esses números demonstram uma alta taxa de predição dos resultados obtidos na seleção em comparação com a avaliação da instrução aérea, sendo que a taxa de atrito (desligamentos) no CFOAV vem diminuindo ao longo dos anos desde a inserção do TAPMIL no processo seletivo.

Pode-se dizer que os cadetes aviadores que foram desligados da instrução aérea apresentaram dificuldades nas habilidades necessárias para a pilotagem militar que o teste visa mensurar. Aliada a essa falta de habilidade, é conhecido que o estado emocional do cadete contribui significativamente para o seu desempenho, prejudicando-o em seu aprendizado. Dentre as variáveis levantadas pelo psicólogo de esquadrão da AFA — que realiza acompanhamento da instrução aérea - que influenciam negativamente o desempenho do cadete aviador na instrução aérea básica levando-o ao fracasso nessa instrução, destacam-se o alto nível de ansiedade diante da instrução aérea, desmotivação com a atividade aérea, excesso de autocobrança em relação ao desempenho na atividade aérea, dificuldades em ter iniciativa e tomar decisões durante o voo, sendo que com isso se tornam dependentes da ajuda do instrutor de voo, dificuldade de adaptação à atividade aérea provocada pela aerocinetose (enjoo aéreo), entre outras.

Griffin e Koonce (1996) sugerem que a maior parte do atrito no treinamento da Força Aérea dos Estados Unidos (USAF) ocorre mais pelo fator motivacional do que pela habilidade na pilotagem, sendo que se pode observar que o fator motivacional também é o responsável por desligamentos na AFA. Porém, vale ressaltar que o TAPMIL, assim como outros testes de seleção de pilotos utilizados no mundo, não avalia o estado emocional do candidato ou o nível de motivação, tampouco sua personalidade.

\section{Considerações finais}

Esta nota técnica teve como objetivo apresentar os esforços realizados para a melhoria da seleção de pilotos militares por meio da utilização do sistema PILAPT, denominado TAPMIL no Brasil, como um instrumento para a seleção de pilotos militares da $\mathrm{FAB}$, tendo como intuito a diminuição dos desligamentos de cadetes aviadores do referido curso de formação, aumentando, assim, a qualidade dos candidatos que desejam ser pilotos militares.

\section{Referências}

Anastasi, A., \& Urbina, S. (2000). Testagem psicológica. (7a ed.). Porto Alegre, RS: Artmed.

Costa, M. P. (2010). Estudo de normatização e validação do Teste de Aptidão para a Pilotagem Militar. Dissertação de Mestrado, Instituto de Psicologia, Universidade de São Paulo, São Paulo.

Griffin, G. R., \& Koonce, J. M. (1996). Review of psychomotor skills in pilot selection research of the U. S. Military Services. International Journal of Aviation Psychology, 6(2), 125-147.

Hunter, D. R., \& Burke, E. (1995). Handbook of pilot selection. Farnham, Inglaterra: Ashgate Publishing Ltd.

Kokorian, A. (1999). The Pilot Aptitude Tester (PILAPT) Handbook. Inglaterra: People Technologies.

Martinussem, M. (1996). Psychological measures as predictors of pilot performance: A meta-analyses. International Journal of Aviation Psychology, 6(1), 1-20.

\section{Sobre os autores}

Maurício Pereira da Costa é psicólogo e doutor em Psicologia Escolar e do Desenvolvimento Humano pelo Instituto de Psicologia da Universidade de São Paulo (USP).

Irai Cristina Boccato Alves é é psicóloga e doutora em Psicologia Escolar e do Desenvolvimento Humano pelo Instituto de Psicologia da Universidade de São Paulo (USP), atualmente é professora da Universidade de São Paulo (USP) na graduação e pós-graduação. 